\title{
Screening for mitochondrial cytopathies: the sub-anaerobic threshold exercise test (SATET)
}

\author{
LINA NASHEF, RUSSELL J M LANE \\ From the Regional Neurosciences Centre, Charing Cross Hospital, London
}

SUMMARY A simple test is described for identifying patients with abnormalities of muscle energy metabolism secondary to mitochondrial dysfunction, based on the venous lactate response to exercise at $90 \%$ of predicted work rate at the anaerobic threshold. The test was standardised for age, weight and sex of subjects, and was abnormal in all cases of mitochondrial cytopathy tested, with a false positive rate of $7 \%$ in a control population. The test was abnormal in two cases of mitochondrial disease in which muscle biopsy was normal or showed only non-specific changes.

The wide clinical spectrum of disorders related to biochemical and structural abnormalities of the mitochondria is being increasingly recognised. These disorders can present with progressive muscle weakness, particularly of the extra-ocular muscles, exertional myalgia, central and peripheral nervous system dysfunction and symptoms secondary to periodic lactic acidosis; other organ systems such as the heart, liver, kidneys, the haemopoetic system, and endocrine glands may also be involved. ${ }^{1-3}$ Investigations to confirm the diagnosis of mitochondrial cytopathy typically include measurements of serum muscle enzymes, plasma lactate, electromyography, and muscle biopsy (histology, histochemistry and electron microscopy), but further investigations such as assays of specific components of the respiratory chain, ${ }^{4}{ }^{31} \mathrm{P}$-magnetic resonance spectroscopy of muscle, ${ }^{5}$ and positron emission tomography of brain ${ }^{6}$ may be required to establish the diagnosis and to define the metabolic defect. However, such tests are complex and expensive and it is therefore important that a simple screening test is available to allow appropriate selection of cases for further investigation.

A number of defects have been identified in the aerobic utilisation of pyruvate via acetyl CoA, the citric acid cycle and the respiratory chain in the mitochondrial cytopathies ${ }^{1-3}$ and a common consequence of such defects is the secondary increased

Correspondence to: Dr R J M Lane, Charing Cross Hospital, Fulham Palace Road, London W6 8RF, UK.

Received 3 February 1989.

Accepted 22 March 1989 conversion of pyruvate to lactate through anaerobic glycolysis. Resting lactate levels in such patients are often normal, however, ' and exercise may be required to demonstrate this abnormality. Although exercise testing is regularly performed in the investigation of mitochondrial disorders, published protocols do no clearly state the workload. Exercise regimens hav ranged from minutes 7 to several hours ${ }^{8}$ in duration $\left.{ }^{7}\right)$ and from "light work" to "exercise to exhaustion" and have not been standardised with regard to ageg weight and sex of subjects.

The plasma lactate concentration depends on the balance between lactate production and removal by the tissues, including muscle. ${ }^{9}$ When exercise work rate is increased incrementally, a point is reached at which lactate level rises sharply. This essentially corresponds to the anaerobic threshold (AT) in terms of oxygen consumption $^{10}$ (although the lactate and oxygen utilisation responses during exercise are in fact independent ${ }^{11}{ }^{12}$ ). AT has been measured in normal untrained volunteers during incremental exercise testing using ventilatory variables ${ }^{1314}$ and lactate concentrations, ${ }^{10}$ and tables based on such measurements allow the work rate and heart rate at the AT to be predicted (table 1). We elected to exercise subjects at a steady state below their predicted AT, on the premise that rises in venous lactate in normal people at such work rates should be of small magnitude, whereas a decrease in AT, as might be anticipated in patients with mitochondrial cytopathy, should lead to an abnormally large rise. In this paper, we describe the sub-anaerobic threshold exercise test (SATET) and our preliminary results in 29 normal volunteers, and in six patients with mitochondrial cytopathies. 
Table 1 Predicted work rates in Watts/kg at AT (Mean values from data of Reinhardt et al ${ }^{10}$ )

\begin{tabular}{llllllll}
\hline Age $(y r)$ & & & & & & \\
\hline $20-29$ & & $30-39$ & & $40-49$ & & $50-56$ & \\
\hline M & F & M & F & M & F & M & F \\
1.07 & 1.06 & 1.05 & 1.06 & 1.01 & 0.85 & 0.76 & 0.76 \\
\hline
\end{tabular}

\section{Methods}

\section{Patients and control subjects}

Six patients with clinical features of the spectrum of disorders usually referred to as "chronic progressive external ophthalmoplegia-plus" (CPEO-plus) were studied. In addition to external ophthalmoplegia and ptosis, all had degrees of facial and limb muscle weakness, together with clinical signs of a peripheral neuropathy. Cases 2, 3, 5 and 6 had dysphagia, and case 5 also had diabetes and sensorineural deafness. Table 2 outlines some of their additional clinical features. Fifteen normal female and 14 normal male volunteers recruited from the clerical, nursing, laboratory and medical staff were also studied.

\section{Exercise regime}

Subjects were weighed and the AT was calculated according to age, weight and sex from the data of Reinhard ${ }^{10}$ (table 1). Exercise consisted of pedalling an electronically-braked bicycle ergometer (Lode NV, Gronigen, Holland) at $60 \mathrm{rpm}$ for up to 15 minutes at $90 \%$ of the predicted work rate at AT . Venous blood samples were taken prior to exercise, immediately after, and 30 minutes after completion of exercise. ECG characteristics were monitored throughout the procedure using a computerised ECG system (Marquette Case, Marquette Electronics Inc. Milwaukee, Wisconsin) which automatically provided a minute to minute record of heart rate from which mean and maximum heart rate during exercise could be derived. Predicted heart rates at AT were derived from the data of Reinhard ${ }^{10}$ and from unpublished studies linking heart rate and oxygen consumption (Appendix).

\section{Lactate measurements}

Samples for venous lactate measurement were collected in fluoride containers. Plasma was separated immediately and protein precipitated with $0.8 \%$ perchloric acid to obtain a stable, protein-free supernatant for analysis using a standard coupled-enzyme technique (Sigma L+(lactate) 826-UV, Sigma, Poole, Dorset).

\section{Results}

\section{Plasma lactate levels}

All the patients managed a satisfactory exercise test with no complications, although fatigue and myalgia prevented two of the patients from exercising for the full 15 minutes (table 3). All control subjects completed 15 minutes of exercise without difficulty.

Pre-, post- and $30^{\prime}$ post-exercise venous lactate levels in male and female control groups were first analysed by one-sample Kolmogorov-Smirnov tests and shown to be normally distributed. Student's $t$ test for unpaired samples was used for analysis throughout. Pre-exercise lactate concentrations were similar in males and females and there was no significant difference between levels in patients and controls. Post-exercise lactate levels were significantly lower in normal males than females, but levels in the patients were significantly higher than controls irrespective of age or sex. The $30^{\prime}$ post-exercise lactate levels were comparable in males and females, but were significantly greater in the patients than in the controls. Table 4 shows the means and upper $99 \%$ confidence limits for the control groups.

Only 2/29 controls had a peak lactate greater than $5 \mathrm{mM}$ (fig 1). These two subjects were both female, and aged 43 and 49 years. Using $5 \mathrm{mM}$ as a convenient "cut-off" for the normal upper limit for peak lactate in the test, the sensitivity (positivity in disease) in the patients with mitochondrial cytopathy was $100 \%$ and the specificity (negativity in health) was $93 \%$. While $30^{\prime}$ post-exercise lactate levels tended to be higher in patients than controls, there was considerable overlap between the two groups and these measurements did not provide sufficient discrimination in individual cases.

Table 2 Additional clinical and laboratory data in CPEO-plus patients

\begin{tabular}{|c|c|c|c|c|c|c|c|c|c|c|}
\hline & Age (y) & Sex & Myalgia & Ataxia & Deafness & $\begin{array}{l}\text { Cataracts/ } \\
\text { retinal } \\
\text { pigmentation }\end{array}$ & $C K$ & $E M G$ & $M R S$ & Biopsy \\
\hline $\begin{array}{l}1 \\
2 \\
3 \\
4 \\
5 \\
6\end{array}$ & $\begin{array}{l}36 \\
59 \\
58 \\
76 \\
59 \\
60\end{array}$ & $\begin{array}{l}\mathbf{F} \\
\mathbf{M} \\
\mathbf{F} \\
\mathbf{F} \\
\mathbf{M} \\
\mathbf{M}\end{array}$ & $\begin{array}{l}+ \\
+ \\
+1- \\
+1- \\
+ \\
+\end{array}$ & $\begin{array}{l}- \\
- \\
- \\
+1- \\
+1- \\
+\end{array}$ & $\begin{array}{l}- \\
- \\
- \\
+ \\
+\end{array}$ & $\begin{array}{l}- \\
+ \\
- \\
- \\
+ \\
+\end{array}$ & $\begin{array}{l}\mathbf{N} \\
\uparrow \\
\mathbf{N} \\
\mathbf{N} \\
\uparrow \uparrow \\
\uparrow\end{array}$ & $\begin{array}{l}+ \\
+ \\
+ \\
+ \\
+\end{array}$ & $\begin{array}{l}\mathbf{N} \\
+ \\
\mathbf{N} \\
- \\
- \\
-\end{array}$ & $\begin{array}{l}\mathrm{N} \\
+ \\
\mathrm{n} / \mathrm{s} \\
+ \\
+ \\
+\end{array}$ \\
\hline
\end{tabular}

CK, creatine kinase level $\uparrow$ raised or $\mathrm{N}$ normal. EMG + myopathic changes or $\mathrm{N}$ normal on electromyography. MRS ${ }^{31} \mathrm{P}$ spectroscopy of muscle + abnormal or $\mathrm{N}$ normal. Biopsy + mitochondrial abnormalities on muscle biopsy, $\mathrm{n} / \mathrm{s}$ non-specific changes or $\mathrm{N}$ normal. - not done. 
Table 3 SATET data in CPEO-plus patients

\begin{tabular}{|c|c|c|c|c|c|c|c|}
\hline \multirow[b]{2}{*}{ Case } & \multirow[b]{2}{*}{$\operatorname{Age}(y)$} & \multicolumn{2}{|c|}{ Exercise performed } & \multicolumn{3}{|c|}{ Lactate $m M$} & \multirow[b]{2}{*}{$($ Mean-pred $H R) A T$} \\
\hline & & Min & Mean heart rate & Pre & Post & $30^{\prime}$ post & \\
\hline
\end{tabular}

* Level at end of exercise - data not obtained.

Table 4 Comparison of venous lactate levels in control and patient group

\begin{tabular}{|c|c|c|}
\hline \multirow{3}{*}{$\begin{array}{l}\text { Mean, SD } \\
\text { Upper } 99 \% \mathrm{CL}\end{array}$} & \multicolumn{2}{|l|}{ Pre-exercise lactates $m M$} \\
\hline & $\begin{array}{l}\text { Controls }(\mathrm{n}=28) \\
1 \cdot 104,0 \cdot 508 \\
1 \cdot 37\end{array}$ & $\begin{array}{l}\text { Patients }(\mathrm{n}=6) \\
1.467,0.446\end{array}$ \\
\hline & \multicolumn{2}{|l|}{ Post-exercise lactates $m M$} \\
\hline $\begin{array}{l}\text { Mean, SD } \\
\text { Upper } 99 \% \text { CL }\end{array}$ & $\begin{array}{ll}\text { Controls } & \\
\text { Males }(\mathrm{n}=14) & \text { Females }(\mathrm{n}=15) \\
1.768 \pm 0.524 & 3.334 \pm 1.904 \\
2.19 & 4.83\end{array}$ & $\begin{array}{l}\text { Patients } \\
7 \cdot 276,2 \cdot 268^{*}\end{array}$ \\
\hline & \multicolumn{2}{|l|}{$30^{\prime}$ post-exercise lactates $\mathrm{mM}$} \\
\hline $\begin{array}{l}\text { Mean, SD } \\
\text { Upper } 99 \% \text { CL }\end{array}$ & $\begin{array}{l}\text { Controls }(\mathrm{n}=29) \\
1 \cdot 212 \pm 0.611 \\
1 \cdot 529\end{array}$ & $\begin{array}{l}\text { Patients } \\
2 \cdot 817,1 \cdot 177^{*}\end{array}$ \\
\hline
\end{tabular}

*Patients $>$ Controls, $\mathrm{p}<0.001$.

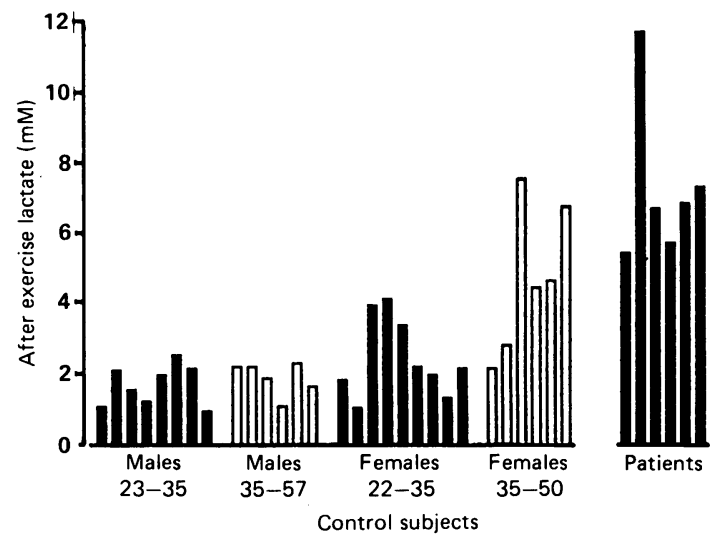

Fig 1 Post-exercise venous plasma lactate levels in 29. control subjects and 6 patients with mitochondrial cytopathies.

\section{Heart rate changes}

Mean heart rates in controls during exercise varied between 96 and 166 beats/minute, and were generally higher in females. Responses in patients were similar (table 3). Figure 2 shows the (mean-predicted) heart

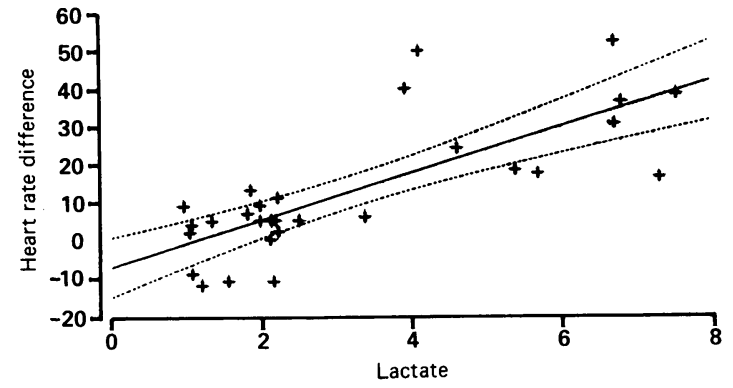

Fig 2 Mean-predicted heart rates at AT in the control subjects and CPEO-plus patients, plotted against postexercise lactate levels, with $95 \%$ confidence limits for the samples. A linear relationship was found between these variables: (mean-predicted $H R_{A T}$ ) $=6.067$. Lactate 6.973. The association was significant with $r=0.755$, $p<0.001$.

rates for both patients and controls during exercise. $A$ linear correlation relating these variables was found $(r=0.755, p<0.001)$. In the majority of subjects, the differences were small (less than 15 beats/minute), but were higher (16 to $52 / \mathrm{min}$ ) when peak lactate values exceeded $5 \mathrm{mM}$.

\section{Discussion}

The development of techniques to study mitochondrial biochemistry both in vivo and in vitro has been of considerable importance in neurobiology and a number of previously enigmatic conditions have been shown to be due to abnormalities of mitochondrial function..$^{1-3}$ The classification of these disorders is difficult. Particular biochemical abnormalities can lead to a range of clinical presentations, presumably reflecting the significance and extent of the molecular lesion and the number and distribution of abnormal mitochondria in the body. Conversely, a recognisable syndrome associated with mitochondrial abnormality may result from a number of different biochemical defects. For example, patients with "CPEO-plus" 
have been shown to have deficiencies of various enzyme complexes on the respiratory chain. ${ }^{1-3}$

The diagnosis of mitochondrial cytopathy and identification of the biochemical defect in these patients is of more than academic importance. The clinical and pathological consequences of the metabolic disorder progress with time, ${ }^{15}$ but some cases respond to treatment with thiamine, ${ }^{16}$ riboflavin ${ }^{17}$ or Coenzyme $Q .^{18}$ While the diagnostic "gold standard" for mitochondrial cytopathies remains that of a positive muscle biopsy, characterised by sub-sarcolemmal accumulations of abnormal mitochondria on oxidative enzyme staining and electron microscopy, ${ }^{1-3}$ biopsy may show no abnormalities in routine histological and histochemical preparations. ${ }^{19-21}$ The diagnosis in our patients was made on the basis of clinical presentation and supportive laboratory investigations, but it should be noted that not all patients had abnormal muscle biopsies. Case 3, for example, had only minor nonspecific abnormalities on biopsy, but presented with an identical clinical picture to that of her brother (case 2), whose biopsy specimen showed changes typical of a mitochondrial myopathy.

The main advantage of the SATET in the diagnosis of disorders of energy metabolism is its simplicity and high sensitivity under standardised conditions, using defined work rates. Johnson et al ${ }^{20}$ exercised subjects at " $30 \%$ of maximal work rate" and measured venous lactate at rest and at 5 and 15 minutes in one patient with CPEO plus and five controls; little change was recorded in post-exercise levels. Morgan-Hughes et al ${ }^{7}$ used an exercise test which consisted of "pedalling a standard exercise ergometer without added load for a period of five or fifteen minutes at a rate of approximately $10 \mathrm{~km} / \mathrm{hr}$ ". An "appropriate" exercise time and work load was then selected following a series of trials. In a subsequent report, ${ }^{2}$ the work load was adjusted to produce a heart rate of "approximately 150 beats/minute", with venous lactate samples being taken at 5 minute intervals during exercise and at 5,15 , 30,45 and 75 minutes after exercise. The maximum peak exercise lactate concentration in 14 normal and disease controls was $1.8 \mathrm{mM}$. In 19/29 patients with mitochondrial myopathies, peak lactate concentrations rose to $2 \mathrm{mM}$ or greater, but remained below this level in the other 10 cases, giving a test sensitivity of $66 \%$. Using the regime described here, all cases of mitochondrial cytopathy had peak lactates greater than $5 \mathrm{mM}$, and the specificity of the test at this level was $93 \%$.

Subjects showing abnormal peak lactate levels also had mean heart rates which were substantially above predicted rates at AT (fig 2). This "hyperkinetic circulatory response" in patients with presumed defects in muscle oxidative phosphorylation was recognised in early studies of patients with limited exercise tolerance and increased lactate and pyruvate concentrations in the blood, and was shown to be a cardiovascular response to vasodilatation and arteriovenous shunting in the muscles, presumably induced by excessive accumulation of metabolites. ${ }^{22}$

Obviously, an abnormal result on such a test cannot be considered specific for metabolic muscle disease. An increased plasma lactate response to exercise might occur under other circumstances, such as impaired oxygen delivery to the muscles in anaemia or cardiorespiratory disease. ${ }^{12}$ Lactate production by muscle is also influenced by cardiovascular fitness and training. Aerobic training increases AT, decreasing the amount of lactate released at a given workload. ${ }^{23}$ We did not rigorously assess the amount of leisure-time exercise undertaken by our controls but none were in regular training, and were in this respect comparable to the patients, all of whom were mobile and active. An abnormal result might also arise if there was reduced re-uptake of released lactate by muscle, in patients with reduced muscle bulk. We have studied three patients with motor neuron disease; one with limited mobility and significant muscular atrophy had an abnormal peak lactate of $5.7 \mathrm{mM}$, but two other less disabled patients had normal results.

Although non-specific, the SATET may be more sensitive than standard muscle biopsies for the diagnosis of mitochondrial cytopathies in cases of progressive external ophthalmoplegia. Whether it will be as useful in cases with predominantly central nervous system involvement is uncertain. We have studied two such cases, aged 26 and 30 years, where the diagnosis was suspected but not confirmed on biopsy. One had Ramsay Hunt syndrome (dyssynergia cerebellaris myoclonica), which has recently been shown to be a mitochondrial cytopathy by ${ }^{31} \mathrm{P}-\mathrm{NMR}$ spectroscopy, ${ }^{24}$ and the other an undefined disorder characterised by marked exercise intolerance, intermitten encephalopathy with lactic acidaemia and raised serum creatine kinase levels, migrainous headaches, short stature and mild mental retardation. Both had abnormal peak lactate levels of 8.2 and $7.4 \mathrm{mM}$ respectively, in the SATET.

The test might also find a role in the evaluation of chronic fatigue and myalgia. These are common and sometimes disabling symptoms, which, since even detailed investigation rarely defines a cause, ${ }^{25}$ are often considered to be psychogenic. Yet evaluation of such patients only rarely includes assessment of performance under the very conditions which produce or exacerbate the symptoms.

We recommend the sub-anaerobic threshold exercise test as a sensitive screening investigation for patients with suspected metabolic muscle disease. It avoids the discomfort, inconvenience and risks of high 
work rates and prolonged testing, and is very simple to perform. Care should be taken if there is any suspicion of significant cardiac disease, and although we have not experienced such complications in any of the subjects tested to date, we would suggest that the test is performed with continuous cardiac monitoring.

We thank Professor A Guz, Mr R Hamilton and Mr R Lane for access to the ergometer and for technical advice, and Dr B Muller and colleagues for performing the lactate assays.

\section{References}

1 DiMauro S, Bonilla E, Zeviani M, Nakagawa M, DeVivo D. Mitochondrial myopathies. Ann Neurol 1985;17:521-38.

2 Petty RKH, Harding AE, Morgan-Hughes JA. The clinical features of mitochondrial myopathy. Brain 1986;109:915-38.

3 DiMauro S, Bonilla E, Zeviani M, Servidei S, DeVivo DC, Schon EA. Mitochondrial myopathies. J Inher Metab Dis 1987;10 (Supp 1):113-28.

4 Sherratt HSA, Watmough NJ, Johnson MA, Turnbull DM. Methods for the study of normal and abnormal skeletal muscle mitochondria. Methods Biochem Anal 1988;33:243-335.

5 Arnold DL, Taylor DJ, Radda GK. Investigation of human mitochondrial myopathies by phosphorus magnetic resonance spectroscopy. Ann Neurol 1985;18:189-96.

6 Frackowiak RSJ, Herold S, Petty RKH, Morgan-Hughes JA. The cerebral metabolism of glucose and oxygen measured with positron tomography in patients with mitochondrial diseases. Brain 1988;111:1009-24.

7 Morgan-Hughes JA, Darveniza P, Kahn SN, Landon DN, Sherratt RM, Land JM, Clark JB. A mitochondrial myopathy characterised by a deficiency in reducible cytochrome b. Brain 1977;100:617-40.

8 Brooke MH, Carroll JE, Davis JE, Hagberg JM. The prolonged exercise test. Neurology 1979;29:636-43.

9 Poortmans JR, Delescaille-Van den Bossche J, Leclercq R. Lactate uptake by inactive forearm during progressive leg exercise. $J$ Appl Physiol 1978;45:835-9.

10 Reinhard U, Muller PH, Schmulling RM. Determination of anaerobic threshold by the ventilation equivalent in normal individuals. Respiration 1979;38:36-42.

11 Davis HA, Gass GC. The anaerobic threshold as determined before and during lactic acidosis. Eur J Appl Physiol 1981;47:141-9.

12 Aunola S, Rusko H. Aerobic and anaerobic thresholds determined from venous lactate or from ventilation and gas exchange in relation to muscle fibre composition. Int J Sports Med 1986;7:161-6.

13 Wasserman K, Whipp BJ, Davis JA. Respiratory physiology of exercise: Metabolism, gas exchange and voluntary control. Int Rev Physiol (Resp Physiol III) 1981;23:149-211.

14 Jones NL, Makrides L, Hitchcock C, Chypchar T, McCartney N. Normal standards for an incremental cycle ergometer test. Am Rev Resp Dis 1985;131:700-8.

15 Bresolin N, Moggio M, Bet L, Gallanti A, Prelle A, Nobile-Orazio
E, Adobbati L, Ferrante C, Pellegrini G, Scarlato G. Progressive cytochrome $c$ deficiency in a case of Kearns-Sayre syndrome: Morphological, immunological and biochemical studies in muscle biopsies and autopsy tissues. Ann Neurol 1987;21:564-72.

16 Mastaglia FL, Thompson PL, Papadimitriou JM. Mitochondrial myopathy with cardiomyopathy, lactic acidosis and response to prednisone and thiamine. Aust N Z Med J 1980;10:660-4.

17 Arts WFM, Scholte HR, Bogaard JM, Kerrebijn KF, LuytHouwen IEM. NADH-CoQ reductase deficiency myopathy: Successful treatment with riboflavin. Lancet 1983;ii:582-3.

18 Ogasahara S, Nishigawa Y, Yorifugi S, et al. Treatment of KearnsSayre syndrome with $Q_{10}$. Neurology 1986;36:45-53.

19 Mitsumoto H, Aprille JR, Wray SH, Nemni R, Bradley WG. Chronic progressive external ophthalmoplegia (CPEO): Clinical, morphological and biochemical studies. Neurology 1983;33:452-61.

20 Johnson MA, Turnbull DM, Dick DJ, Sherratt HSA. A partial deficiency of cytochrome c oxidase in chronic progressive external ophthalmoplegia. J Neurol Sci 1983;60:31-53.

21 Turnbull DM, Johnson MA, Dick DJ, Cartlidge NEF, Sherratt HSA. Partial cytochrome $c$ oxidase deficiency without subsarcolemmal accumulation of mitochondria in progressive external ophthalmoplegia. J Neurol Sci 1985;70:93-100.

22 Linderholm H, Muller R, Ringqvist T, Sornas R. Hereditary abnormal muscle metabolism with hyperkinetic circulation during exercise. Acta Med Scand 1969;185:153-66.

23 Ward GR, MacDougall JD, Sutton JR, Toews CJ, Jones NL. Activation of human muscle pyruvate dehydrogenase with activity and immobilisation. Clin Sci 1986;70:207-10.

24 Berkovic SF, Andermann F, Karpati G, Carpenter S, Andermann B, Shoubridge E. Mitochondrial encephalomyopathies: a solution to the problem of the Ramsay Hunt syndrome. Neurology 1987;37 (suppl 1).

25 Byrne E, Trounce I. Chronic fatigue and myalgia syndrome: mitochondrial and glycolytic studies in skeletal muscle. $J$ Neurol Neurosurg Psychiatry 1987;50:743-6.

\section{Appendix}

Prediction of Heart Rate at the Anaerobic Threshold

From Reinhard et $a l^{10}$ :

Males: $\quad$ V02(AT) $=1 \cdot 296-0 \cdot 0068$. Age

Females: $\quad \mathrm{V}_{02}(\mathrm{AT})=1.006-0.0051$. Age

From unpublished laboratory data on 11 normal subjects and six controls:

Males: $\quad H R=\left(40 \cdot 6 . V_{02}\right)+63 \cdot 7$

Females: $\quad H R=\left(70 \cdot 8 . V_{02}\right)+55 \cdot 4$

Thus:

Males: $\quad$ HRAT $=116 \cdot 3-0 \cdot 276$. Age

Females: $\quad$ HRAT $=126 \cdot 6-0 \cdot 361$. Age

Where $V_{02}$ is the rate of oxygen consumption in litres/min, $\mathrm{HR}$ the heart rate in beats/min, and AT is the anaerobic threshold 